\title{
A case report of bilateral pseudo-doubling of the optic discs
}

\author{
Yi-Xuan Xu ${ }^{1,2}$, Yi-Hao Fu ${ }^{1,2}$, Mingxia Wen ${ }^{1}$, Fengni Lu ${ }^{1}$, Yahui Yang ${ }^{1}$, Jinmei Sha ${ }^{1}$, Jie Zhang ${ }^{1}$ \\ ${ }^{1}$ Department of Ophthalmology, Tangdu Hospital, Air Force Military Medical University, Xi'an, China; ${ }^{2}$ School of Basic Medicine, Air Force \\ Medical University, Xi'an, China \\ Correspondence to: Jie Zhang. Department of Ophthalmology, Tangdu Hospital, Air Force Military Medical University, Xi'an 710038, China. \\ Email: jessicazhangjie@hotmail.com.
}

\begin{abstract}
Doubling of the optic disc is rare in clinic, which appears as true doubling or pseudo-doubling. Bilateral doubling of the optic discs is even more less seen in clinic. Here, we report the case of a 35 -year-old woman who presented to the clinic for a physical examination. The patient's best-corrected visual acuity was 0.6 OD with $+2.25 \mathrm{DS} / 3.50 \mathrm{DC} \times 175^{\circ}$, and $0.9 \mathrm{OS}$ with $-3.00 \mathrm{DS} / 0.50 \mathrm{DC} \times 145^{\circ}$. The intraocular pressure of each eye was normal. Fundoscopy examination revealed an enlarged suspected optic disc in both eyes. Visual field examination revealed an additional blind spot in each eye. Optical coherence tomography (OCT) analysis showed a normal macular thickness and profile. B-scan ultrasound revealed a single optic nerve shadow in each eye. Cranial computed tomography (CT) showed only 1 optic foramen and 1 optic nerve in each eye. Although double-blind spots were demonstrated by visual field examination, and pits in both optic disc regions for both eyes were shown by OCT, it was not enough to support the diagnosis of true doubling of the optic disc. Consequently, the diagnosis of bilateral pseudo-doubling of optic discs was made based on the clinical evidence, leading to the consideration of possible causality of other ophthalmic diseases.
\end{abstract}

Keywords: Case report; optic disc; pseudo-doubling

Submitted Apr 30, 2021. Accepted for publication Jul 31, 2021.

doi: 10.21037/apm-21-1087

View this article at: https://dx.doi.org/10.21037/apm-21-1087

\section{Introduction}

The optic papilla, also known as the optic disc, is a small oval-shaped area on the retina with a diameter of about $1.5 \mathrm{~mm}$ at $3 \mathrm{~mm}$ on the medial side of the macula lutea, marking the site of entrance into the eyeball of the optic nerve. There is a funnel-shaped sunken pit, known as the physiological pit, which is caused by imperfect filling when the optic nerve fibers converge. The central retinal artery and vein enter and exit the eye from the optic papilla (1). They enter the eyeball through the choroid fissure during embryonic development and develop from the proximal segments of vitreous arteries and veins (2). Congenital doubling of the optic disc is rare in the clinic. The clinical reports of unilateral doubling of the optic disc are more common than those of bilateral doubling of the optic disc. The cause of congenital doubling of the optic disc is still unknown, but it is speculated to be related to the overlap of the optic nerve or the division of the distal optic nerve into
2 segments. Most patients have a "main" optic disc and a "satellite" optic disc, each of which has its vascular supply (3). Because of the existence of genetic tendency, it is possible that this condition may be an autosomal recessive genetic disease. We present the following article in accordance with the CARE reporting checklist (available at https://apm. amegroups.com/article/view/10.21037/apm-21-1087/rc).

\section{Case presentation}

We report an extremely rare case of bilateral pseudodoubling of the optic discs in Tangdu Hospital, Air Force Military Medical University. A 35-year-old woman presented to the clinic for a physical examination. The patient's best-corrected visual acuity was $0.6 \mathrm{OD}$ with $+2.25 \mathrm{DS} / 3.50 \mathrm{DC} \times 175^{\circ}$, and $0.9 \mathrm{OS}$ with $-3.00 \mathrm{DS} / 0.50$ $\mathrm{DC} \times 145^{\circ}$. The intraocular pressure of each eye was normal. Examination of the anterior segment was generally normal. The patient had no relevant medical, family, and psycho- 

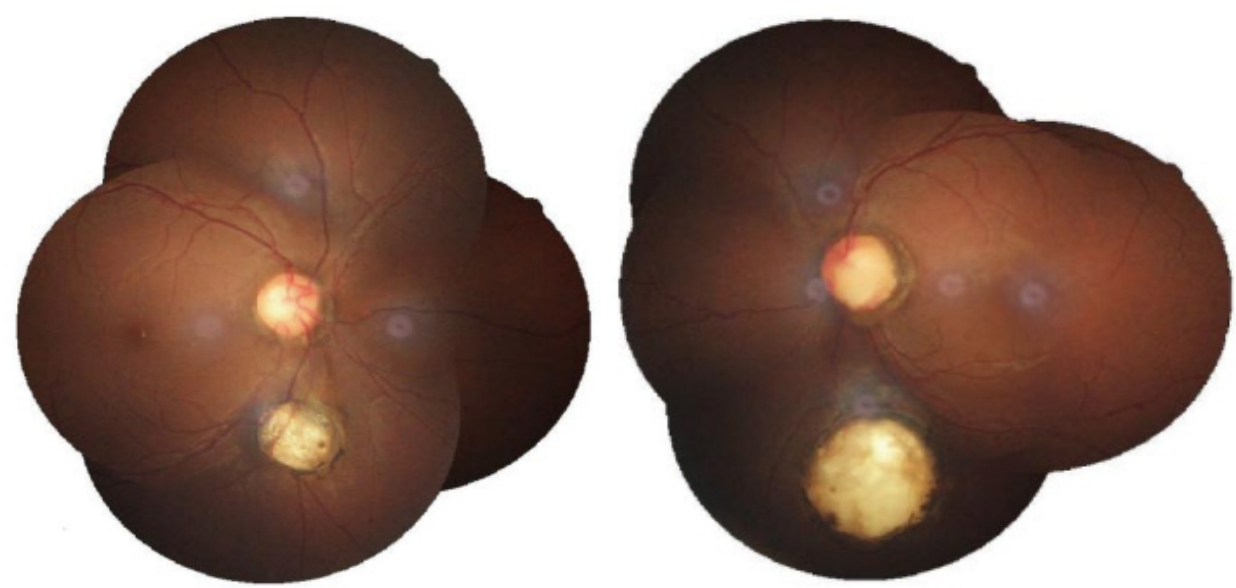

Figure 1 Fundus photography of each eye showing an enlarged suspected optic disc inferiorly.

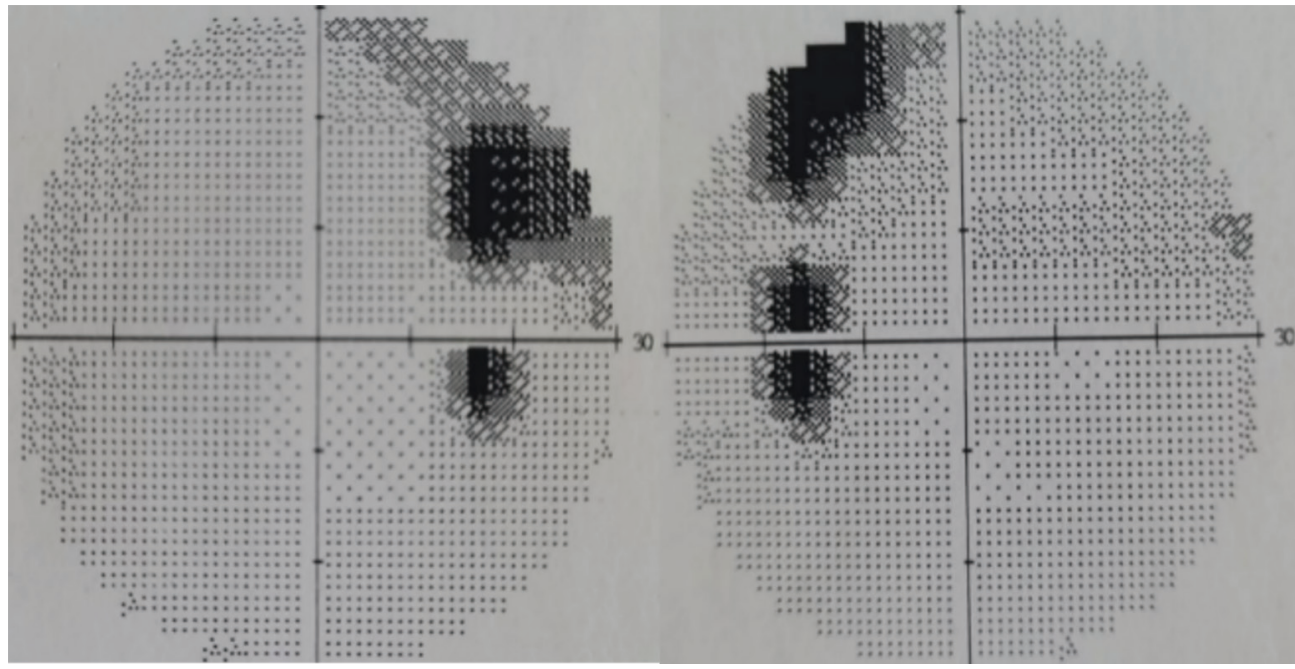

Figure 2 The automated visual field of each eye demonstrating an additional blind spot corresponding to the rudimentary disc with a contiguous arcuate scotoma superiorly.

social history. Fundoscopy examination revealed clear light-red optic discs in both eyes $(\mathrm{C} / \mathrm{D}=0.8)$. An enlarged suspected optic disc was located inferiorly in each eye. The normal inferior temporal vessel of the optic disc passed through the suspected optic disc cup. It was concave and curved (Figure 1). Visual field examination revealed an additional blind spot corresponding to the rudimentary disc with a contiguous arcuate scotoma superiorly in each eye (Figure 2). Optical coherence tomography (OCT) examination showed that areas of the actual and suspected optic discs were sunken in both eyes (Figures 3,4). OCT analysis showed a normal macula thickness and profile
(Figure 5). B-scan ultrasound revealed a single optic nerve shadow in each eye. A second optic nerve was not detected in additional planes (Figure 6). Cranial computed tomography (CT) showed only 1 optic foramen and 1 optic nerve in each eye (Figure 7). All procedures performed in this study were in accordance with the ethical standards of the institutional and/or national research committee(s) and with the Helsinki Declaration (as revised in 2013). Written informed consent was obtained from the patient for publication of this case report and accompanying images. A copy of the written consent is available for review by the editorial office of this journal. 

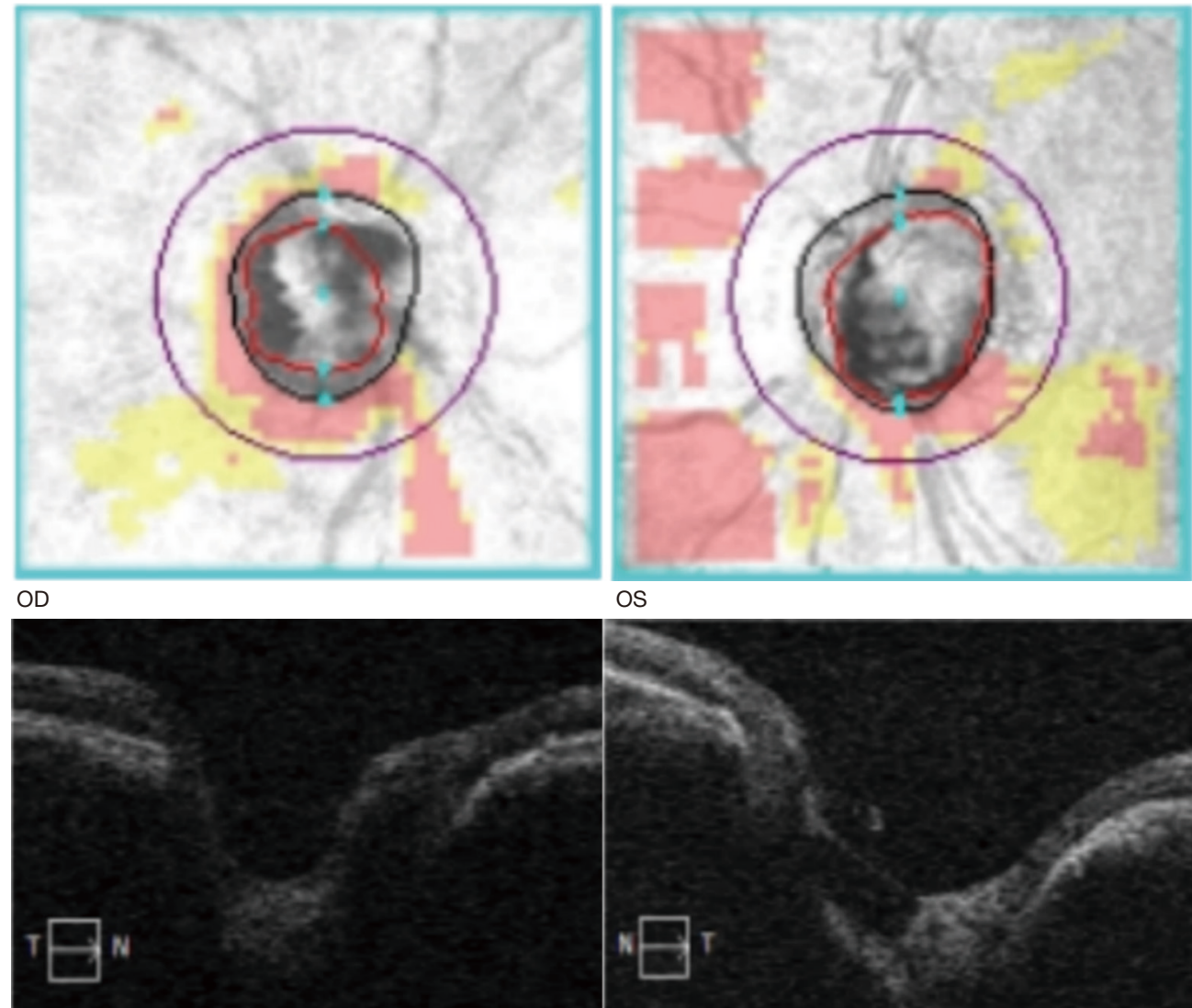

OS

OD

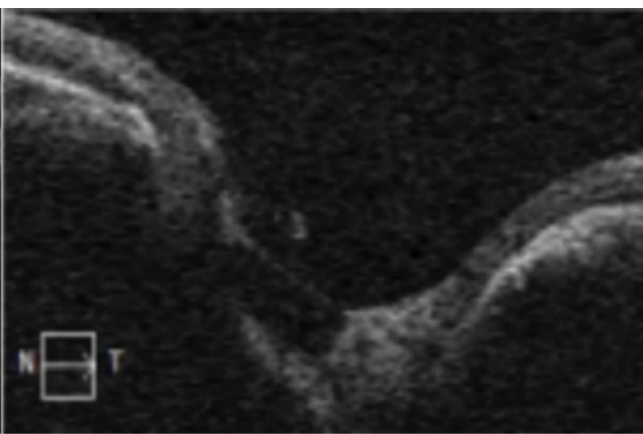

OS

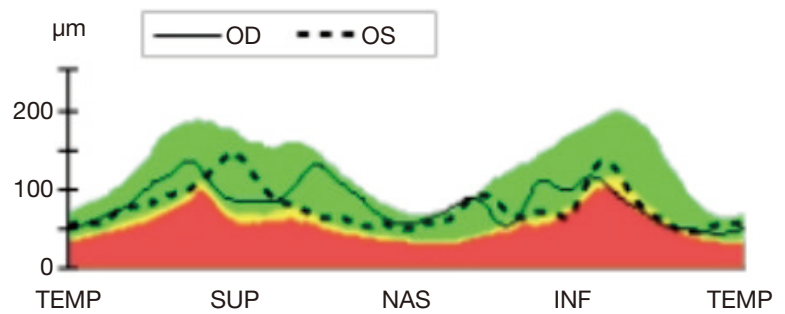

Figure 3 Optical coherence tomography analysis of each main optic disc showing an intact neuroretinal rim $(\mathrm{C} / \mathrm{D}$ ratio $=0.8)$ but normal retinal nerve fiber layer in each eye. OD, oculus dexter; OS, oculus sinister; TEMP, temporal; SUP, superior; NAS, nasal; INF, inferior.

\section{Discussion}

Cases of bilateral doubling of the optic discs are extremely rare and must be differentiated from pseudo-doubling of optic discs $(4,5)$. Previous studies include 3 cases of unilateral doubling of the optic disc $(6,7)$. It can be diagnosed as a true doubling of an optic disc if the suspected optic disc has both optic nerves and an independent vascular supply, or at least one vessel communicating from the actual optic disc (8). Some researchers have indicated that if the nerve fibers of the second optic disc merge into the optic nerve trunk on the inner surface of the sclera, becoming 1 optic nerve at the posterior segment of the eyeball, this can be diagnosed as pseudo-doubling of the optic disc (9).

In our case, the diagnosis of bilateral pseudo-doubling of optic discs was based on the evidence of no independent vascular supply shown on the fundus image. B-scan and cranial CT examinations did not show the presence of 2 optic nerves in either eye, even though the patient did not receive fundus angiography due to contrast agent allergy. Although double-blind spots were demonstrated by visual field examination, and pits in both optic disc regions for both eyes were shown by OCT, it was not enough to support the 

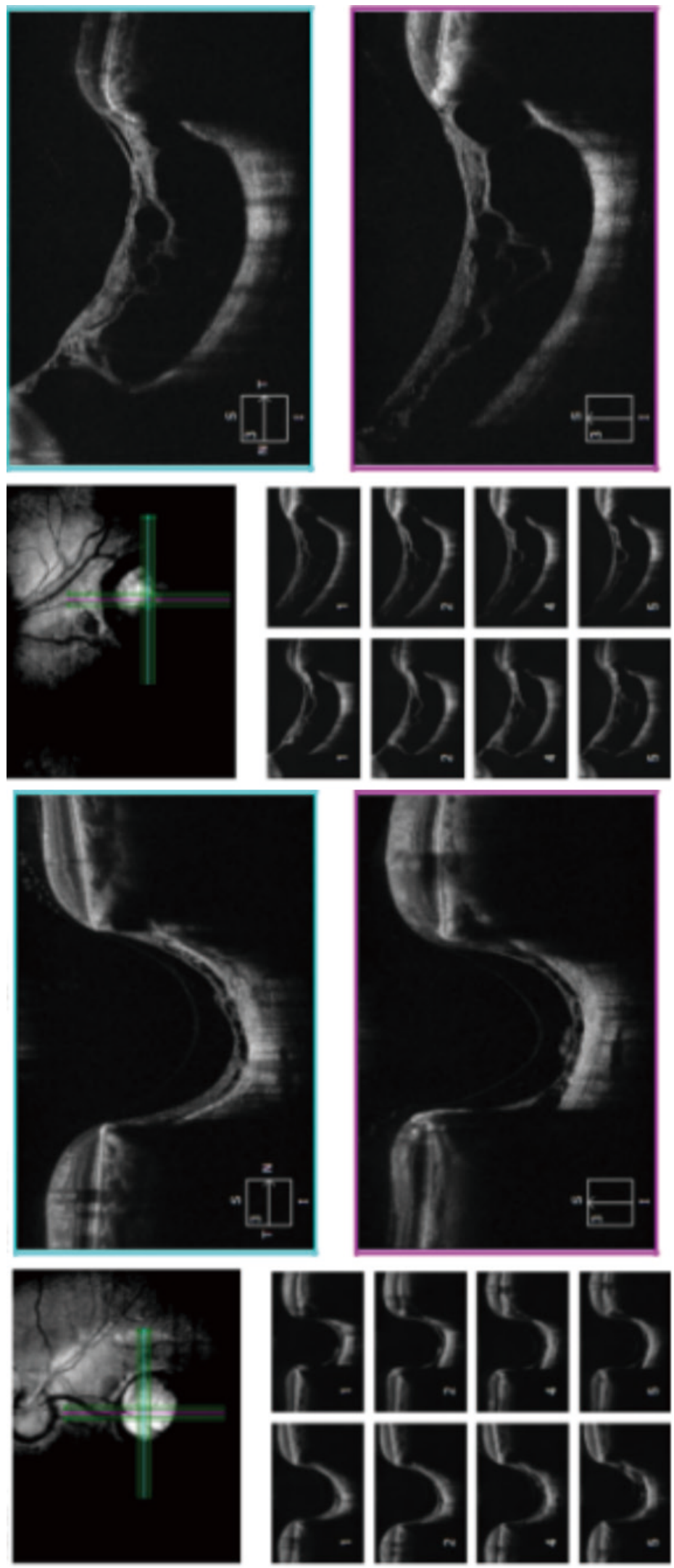

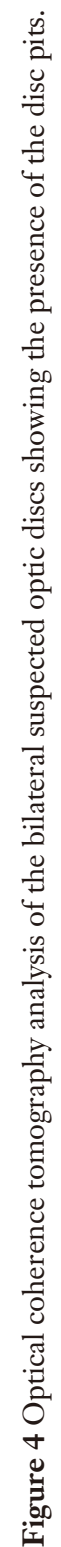




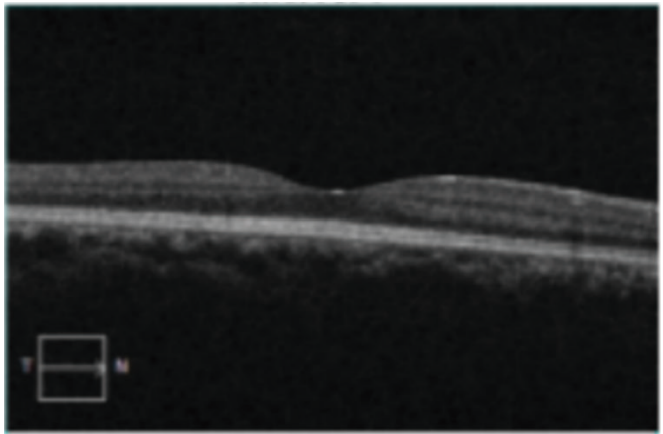

OD

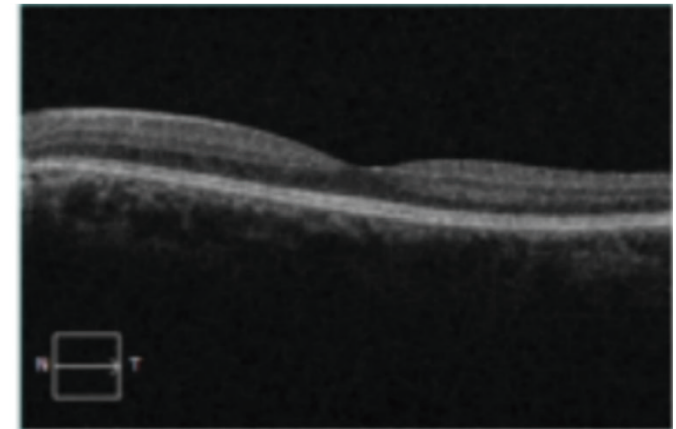

OS

Figure 5 Optical coherence tomography analysis of each eye showing normal macular thickness and profile. OD, oculus dexter; OS, oculus sinister.
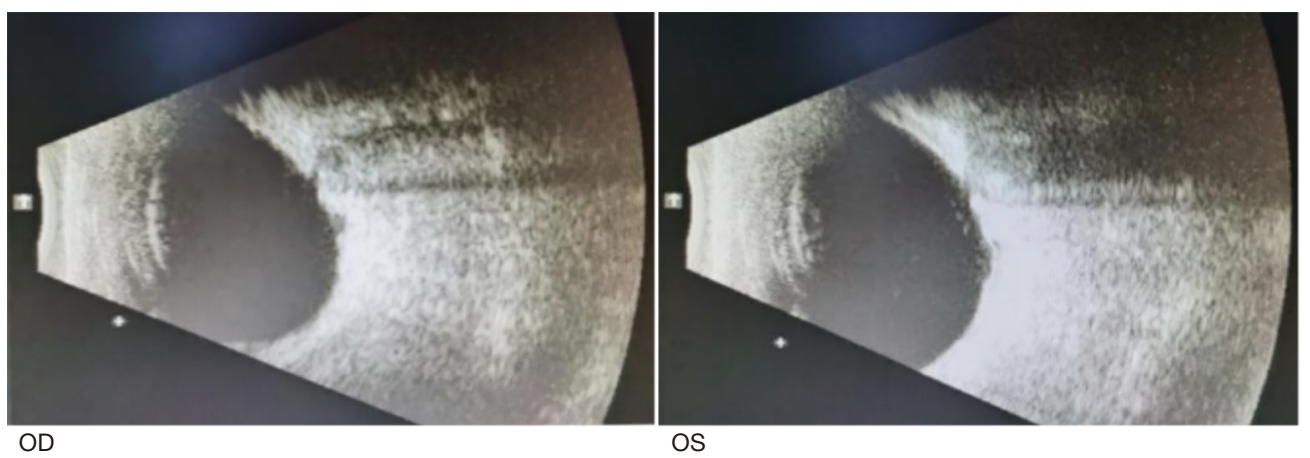

Figure 6 B-scan ultrasound of each eye showing a single optic nerve shadow. A second optic nerve was not detected in additional planes. OD, oculus dexter; OS, oculus sinister.

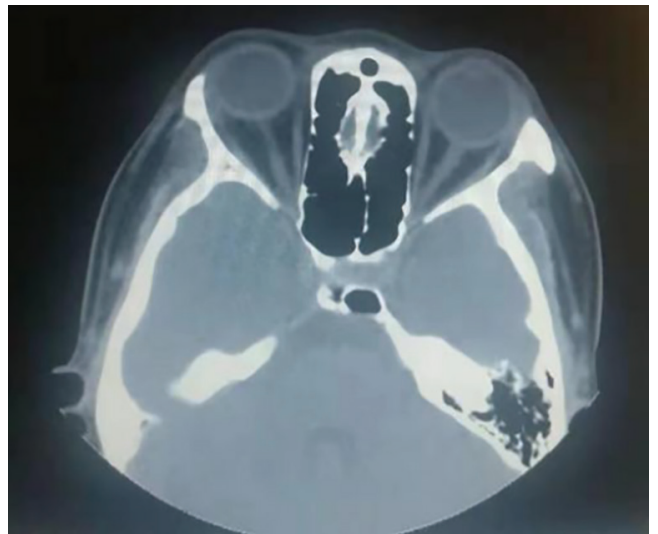

Figure 7 Cranial computed tomography scan showing a single optic nerve in each eye. diagnosis of true doubling of the optic disc. Also, the patient had an increased value of C/D but normal retinal nerve fiber layer thickness and still needs to be closely observed for the possibility of other ophthalmic diseases.

\section{Acknowledgments}

We would like to thank J. Gray and J. Chapnick for their help in polishing our paper.

Funding: None.

\section{Footnote}

Reporting Checklist: The authors have completed the CARE 
reporting checklist. Available at https://apm.amegroups. com/article/view/10.21037/apm-21-1087/rc

Conflicts of Interest: All authors have completed the ICMJE uniform disclosure form (available at https://apm. amegroups.com/article/view/10.21037/apm-21-1087/coif). The authors have no conflicts of interest to declare.

Ethical Statement: The authors are accountable for all aspects of the work in ensuring that questions related to the accuracy or integrity of any part of the work are appropriately investigated and resolved. All procedures performed in this study were in accordance with the ethical standards of the institutional and/or national research committee(s) and with the Helsinki Declaration (as revised in 2013). Written informed consent was obtained from the patient for publication of this case report and accompanying images. A copy of the written consent is available for review by the editorial office of this journal.

Open Access Statement: This is an Open Access article distributed in accordance with the Creative Commons Attribution-NonCommercial-NoDerivs 4.0 International License (CC BY-NC-ND 4.0), which permits the noncommercial replication and distribution of the article with the strict proviso that no changes or edits are made and the original work is properly cited (including links to both the formal publication through the relevant DOI and the license).
See: https://creativecommons.org/licenses/by-nc-nd/4.0/.

\section{References}

1. Liu JQ. Practice of Ophthalmology. 2nd ed. Beijing: People's Medical Publishing House, 2005.

2. Zou ZZ, Li JC. Histology and Embryology. 8th ed. Beijing: People's Medical Publishing House, 2013.

3. Miller NR, Newman NJ, Biousse V, et al. Walsh and Hoyt's: Clinical Neuro-ophthalmology. Beijing: Science Press, 2009.

4. Kamath GG, Prasad S, Patwala YJ, et al. Peripapillary coloboma simulating double optic disc. Br J Ophthalmol 1999;83:1207.

5. Ren Y, Xiao T. Doubling of optic disc. Br J Ophthalmol 2008;92:1151-2.

6. Yuan LH, Feng XM. A case of unilateral doubling of optic disc. Chinese Journal of Experimental Ophthalmology 2019;37:92-3.

7. Cao X, Song L, Xu JJ, et al. Two cases of congenital doubling of optic disc. Chinese Journal of Experimental Ophthalmology 2018;28:96-8.

8. Brink JK, Larsen FE. Pseudodoubling of the optic disc. A fluorescein angiographic study of a case with coloboma. Acta Ophthalmol (Copenh) 1977;55:862-70.

9. Vail D. System of Ophthalmology: Volume III. Normal and Abnormal Development: Part II. Congenital Deformities. Am J Ophthalmol 1964;57:683.
Cite this article as: Xu YX, Fu YH, Wen M, Lu F, Yang Y, Sha J, Zhang J. A case report of bilateral pseudo-doubling of the optic discs. Ann Palliat Med 2022;11(7):2510-2515. doi: 10.21037/apm21-1087 